\title{
PENGARUH TEKNIK RELAKSASI NAFAS DALAM TERHADAP NYERI MENSTRUASI PADA SISWI SMA 3 KOTA PADANGSIDIMPUAN TAHUN 2014
}

\author{
Ratni Siregar, Ramlan Nasution, Elly Indrani Harahap \\ Prodi Kebidanan Padangsidimpuan Poltekkes Kemenkes Medan
}

\begin{abstract}
Abstrak
Nyeri pada saat menstruasi atau haid sering dikeluhkan seorang wanita sebagai sensasi tidak nyaman, bahkan karena timbulnya nyeri tersebut dapat mengganggu aktivitas dan memaksa penderita untuk istrahat dan meninggalkan pekerjaan atau aktivitas rutinnya selama beberapa jam atau beberapa hari. Relaksasi secara umum sebagai metode yang paling efektif terutama pada pasien yang mengalami nyeri sehingga perlu dilakukan penelitian pengaruh terapi relaksasi terhadap nyeri menstruasi. Penelitian ini bertujuan menganalisis perbedaan derajat nyeri menstruasi sebelum dengan sesudah dilakukan terapi relaksasi pada siswi SMAN 3 Padangsidimpuan. Penelitian ini merupakan penelitian observasional dengan disain quasi experimental untuk mengetahui pengaruh relaksasi pernapasan terhadap nyeri menstruasi pada siswi SMAN 3. Jumlah sampel terdiri dari 30 orang yang diambil dengan teknik consecutive sampling. Pengumpulan data diambil melalui hasil kuisioner dan observasi yang diperiksa berdasarkan kriteria inklusi dan eksklusi, dan analisis data berupa analisis univariat dan bivariat dengan menggunakan uji-t berpasangan. Hasil penelitian menunjukkan bahwa umur menarche responden $<11$ tahun ada sebanyak 7 orang $(23,33 \%)$, umur $11-13$ tahun ada sebanyak 15 orang (50\%), dan umur $>14$ tahun ada sebanyak 8 orang $(26,67 \%)$. Sebelum pemberian teknik relaksasi nafas dalam, responden yang merasakan intensitas nyeri ringan ada sebanyak 4 orang $(13,33 \%)$, nyeri sedang ada sebanyak $16(53,33 \%)$ orang, dan nyeri berat ada sebanyak 10 orang $(33,34 \%)$ maka mayoritas responden merasakan intensitas nyeri sedang yaitu sebanyak 16 orang $(53,33 \%)$. Setelah pemberian teknik relaksasi nafas dalam, responden yang merasakan intensitas nyeri ringan ada sebanyak 23 orang $(76,67 \%)$, nyeri sedang ada sebanyak 7 orang $(23,33 \%)$, dan nyeri berat tidak ada $(0 \%)$, maka mayoritas responden merasakan intensitas nyeri ringan sebanyak 23 orang $(76,67 \%)$. Analisis bivariat menunjukkan adanya perbedaan nilai rerata intensitas nyeri sebelum dan setelah perlakuan sebesar 2,93. Dari hasil analisis statistik dengan menggunakan uji $\mathrm{T}$ Berpasangan didapatkan nilai $\mathrm{P}=0,001<\alpha=0,05$ dimana ada perbedaan bermakna antara pre dan post intervensi, maka dapat disimpulkan bahwa ada pengaruh pemberian relaksasi nafas dalam yang signifikan terhadap penurunan intensitas nyeri dismenore pada Siswa SMAN 3 Kota Padangsidimpuan.
\end{abstract}

Kata Kunci : Relaksasi nafas dalam, Nyeri Menstruasi

\section{PENDAHULUAN}

\section{Latar Belakang}

Nyeri pada saat menstruasi atau haid sering dikeluhkan seorang wanita sebagai sensasi tidak nyaman, bahkan karena timbulnya nyeri tersebut dapat mengganggu aktivitas dan memaksa penderita untuk istrahat dan meninggalkan pekerjaan atau aktivitas rutinnya selama beberapa jam atau beberapa hari. Karakteristik nyeri ini sangat khas karena muncul secara reguler dan periodik menyertai menstruasi yaitu rasa tidak enak di perut bagian bawah sebelum dan selama haid disertai mual disebabkan meningkatnya kontraksi uterus. Hal ini dilaporkan sebagai dismenore. Istilah dismenorea (dysmenorrhoea) berasal dari bahasa "Greek"yang artinya dys (gangguan/nyeri hebat/abnormalitas) - meno (bulan) - rrhea ("flow" atau aliran) sehingga dari makna tersebut, dismenore adalah gangguan aliran darah haid atau nyeri haid (Sherwood, 2012).

Wanita yang mengalami nyeri menstruasi (dismenorea) memproduksi prostaglandin 10 kali lebih banyak dari wanita yang tidak dismenorea. Prostaglandin menyebabkan meningkatnya kontraksi uterus, dan pada kadar yang berlebih akan mengaktivasi usus besar. Penyebab lain dismenorea dialami wanita dengan kelainan tertentu, misalnya endometriosis, infeksi pelvis (daerah panggul), tumor rahim, apendisitis, kelainan organ pencernaan, bahkan kelainan ginjal. (Prawirohardjo, 2002).

Studi epidemiologi pada populasi remaja (berusia 12-17 tahun) di Amerika Serikat, Klein dan Litt melaporkan prevalensi dismenorea mencapai 59,7\%. Dari mereka yang mengeluh nyeri, $12 \%$ berat, $37 \%$ sedang, dan $49 \%$ ringan. Studi ini juga melaporkan bahwa dismenorea menyebabkan $14 \%$ remaja sering tidak masuk sekolah. Penelitian tersebut juga menunjukan bahwa tidak ada 
perbedaan prevalensi yang signifikan diantara populasi yang berbeda, Puncak insiden dismenorea primer terjadi pada akhir masa remaja (adolesence) dan di awal usia 20an, insiden dismenorea pada remaja (adolesence) dilaporkan sekitar 92\%. Insiden ini menurun seiring dengan bertambahnya usia dan meningkatnya kelahiran (Wicaksono, 2004). Di lingkungan sekolah SMAN 3 Padangsidimpuan diperkirakan $35 \%$ siswi sering mengalami nyeri menstruasi pada saat menstruasi dan sekitar 5\% siswi SMAN 3 tidak bisa melakukan aktivitas seperti biasanya disebabkan nyeri menstruasi (Survei, 2014).

Rasa ketidaknyamanan jika tidak diatasi akan mempengaruhi fungsi mental dan fisik individu sehingga mendesak untuk segera mengambil tindakan/terapi secara farmakologis atau non farmakologis. Dalam lingkup kebidanan dikembangkan terapi non farmakologis sebagai tindakan mandiri merupakan suatu kelangsungan kondisi kesejahteraan yang melibatkan upaya merawat diri sendiri secara fisik, mengekspresikan emosi dengan benar dan efektif, menggunakan pikiran dengan konstruktif, secara kreatif terlibat dengan orang lain dan upaya memiliki tingkat kesadaran yang lebih tinggi. Terapi non farmakologis atau holistik untuk mengatasi nyeri dapat menggunakan sentuhan terapeutik, akupresur dan relaksasi. Teknik relaksasi memberikan individu kontrol diri ketika terjadi rasa nyeri serta dapat digunakan pada saat seseorang sehat ataupun sakit. (Perry, 2006).

Relaksasi merupakan intervensi mandiri untuk menurunkan intensitas nyeri, meningkatkan ventilasi paru dan meningkatkan oksigenasi darah. Relaksasi otot skeletal dipercaya dapat menurunkan nyeri dengan merilekskan tegangan otot yang menunjang nyeri, ada banyak bukti yang menunjukkan bahwa relaksasi efektif dalam meredakan nyeri (Smeltzer, 2002). Relaksasi secara umum sebagai metode yang paling efektif terutama pada pasien yang mengalami nyeri (National Safety Council, 2003) sehingga perlu dilakukan penelitian pengaruh terapi relaksasi terhadap nyeri menstruasi. Oleh karena itu penelitian ini bertujuan menganalisis perbedaan derajat nyeri menstruasi sebelum dengan sesudah dilakukan terapi relaksasi pada siswi SMAN 3 Padangsidimpuan.

\section{Tujuan Penulisan}

a. Tujuan Umum: Untuk mengetahui pengaruh teknik relaksasi nafas dalam terhadap nyeri menstruasi pada siswi SMA 3 Kota Padangsidimpuan.

b. Tujuan Khusus

a. Untuk mengetahui intensitas nyeri menstruasi sebelum dilakukan teknik relaksasi nafas dalam pada siswi SMA 3 Kota Padangsidimpuan.

b. Untuk mengetahui intensitas nyeri menstruasi setelah dilakukan teknik relaksasi nafas dalam pada siswi SMA 3 Kota Padangsidimpuan.

\section{Hipothesis}

1. Terdapat pengaruh teknik relaksasi nafas dalam terhadap nyeri menstruasi pada siswa SMAN 3 Kota Padangsidimpuan.

\section{Manfaat Penelitian}

a. Manfaat Akademik

Diharapkan penelitian ini dapat memberikan sumbangsih akademik mengetahui pengaruh teknik relaksasi nafas dalam terhadap penurunan intensitas nyeri menstruasi pada remaja.

b. Manfaat Terapan

Diharapkan hasil penelitian ini dapat menjadi bahan masukan pada para bidan dalam memberikan asuhan kebidanan reproduksi pada remaja dengan nyeri menstruasi dengan menggunakan perlakukan teknik relaksasi nafas dalam.

\section{METODE PENELITIAN}

\section{Jenis Penelitian}

Jenis penelitian ini adalah bersifat analitik menggunakan studi quasi eksperimental, yang bertujuan untuk mengetahui pengaruh relaksasi nafas dalam terhadap nyeri menstruasi. Desaian penelitian adalah pre test and post test only non control goup design.

Jenis data yang dikumpulkan adalah data primer. Populasi penelitian ini adalah semua siswi kelas 10 SMA 3 di Kota Padangsidimpuan. Pemilihan sampel dilakukan dengan cara consecutive sampling. Semua subyek yang datang secara berurutan dan memenuhi kriteria pemilihan dimasukkan dalam penelitian sampai jumlah subyek yang diperlukan terpenuhi. Besar sampel dihitung dengan rumus dari Sastroasmoro:

$$
\mathrm{n}=\frac{\left[\begin{array}{lll}
z \alpha & x & s
\end{array}\right]^{2}}{\mathrm{~d}}
$$

$\mathrm{s}=$ simpang baku nilai rerata dalam populasi, $(1,75)$ dari penelitian terdahulu (Wirya, 2013)

$$
\begin{aligned}
\mathrm{d} & =1,5 \\
\alpha & =\text { tingkat kemaknaan } 95 \% \\
\mathrm{n} & =\frac{[1,96 \times 1,75]^{2}}{0,6} \\
& =30 \text { orang }
\end{aligned}
$$

Data yang dikumpulkan dianalisis dengan menggunakan analisis univariat dan analisis bivariat untuk mengetahui hubungan variabel independen dengan variabel dependen dengan pengujian uji- $t$ berpasangan. Analisis bivariat digunakan untuk menyatakan analisis terhadap dua variabel yaitu variabel bebas dan variabel tergantung dengan menggunakan uji-t berpasangan dengan interval kepercayaan 95\% $(\alpha=0,05)$ bila $\mathrm{p}<0,05$ maka variabel dinyatakan signifikan. Penyajian data dalam bentuk tabel dan grafik.

\section{Metode Pengumpulan Data}

Metode pengumpulan data yang digunakan peneliti untuk mengumpulkan data adalah data primer dengan menggunakan lembar observasi yang diisi oleh subjek penelitian. 


\section{Metode Analisa Data}

Data yang dikumpulkan dianalisis dengan menggunakan analisis bivariat untuk mengetahui hubungan variable independen dengan variable dependen dengan pengujian chi-square. Selanjutnya data diuji dengan analisis regresi logistik.

\section{Definisi operasional}

Untuk lebih menjelaskan dan menghindari kesalahan penafsiran beberapa kata/istilah dalam penelitian ini, peneliti merumuskan definisi operasional kata/istilah tersebut berikut ini.

1. Relaksasi nafas dalam

Defenisi : Relaksasi adalah status hilang dari ketegangan otot rangka dimana individu mencapainya melalui praktek nafas dalam yang disengaja (Smeltzer, 2002).

Cara ukur : melakukan nafas dalam dan lambat lewat hidung (menahan inspirasi secara maksimal) dan mengeluarkan nafas perlahanlahan lewat mulut.

Alat ukur : lembar observasi

Hasil ukur: Sebelum dilakukan relaksasi nafas dalam diberi nilai 0 , setelah dilakukan diberi nilai 1

Skala ukur : Nominal

2. Dismenorea

Defenisi : Nyeri saat haid yang dirasakan responden yang terletak pada perut bagian bawah yang timbul tidak lama sebelum atau bersamaan dengan permulaan haid yang berlangsung beberapa jam atau sampai berhari-hari.

Cara ukur : Mengukur tingkat nyeri

Alat ukur : Skala nyeri NRS (skala nyeri numeric)

Hasil ukur : Tingkat Nyeri

Skala ukur : Interval

\section{HASIL PENELITIAN DAN PEMBAHASAN}

\section{Hasil Penelitian}

Penelitian ini dilakukan di SMAN 3 Padangsidimpuan mulai Maret 2014 sampai Agustus 2014. Setelah dilakukan observasi, didapatkan sebanyak 30 orang siswi yang mengalami nyeri menstruasi. Kemudian dilakukan pretest untuk mengetahui intensitas nyeri dan setelah itu dilakukan perlakuan relaksasi nafas dalam dan diukur kembali intensitas nyeri dengan menggunakan kuesioner skala nyeri numerik. Pelaksanaan penelitian ini dilakukan oleh peneliti langsung kepada responden secara perorangan, mulai dari pre test, memberikan perlakuan dan post test. Waktu yang dibutuhkan untuk satu orang responden adalah sekitar 5 - 10 menit untuk perlakuan.
Tabel 1. Distribusi Frekuensi Responden Berdasarkan Umur Menarche Pada Siswa SMAN 3 Kota Padangsidimpuan Tahun 2014

\begin{tabular}{llll}
\hline No & Karakteristik & Frekuensi & $\begin{array}{l}\text { Persentase } \\
(\%)\end{array}$ \\
\hline 1 & $<11$ tahun & 7 & 23,33 \\
2 & $11-13$ thn & 15 & 50 \\
3 & $>14$ tahun & 8 & 26,67 \\
\hline & Total & 30 & 100 \\
\hline
\end{tabular}

Dari tabel 1 diketahui bahwa umur menarche responden $<11$ tahun ada sebanyak 7 orang $(23,33 \%)$, umur 11 - 13 tahun ada sebanyak 15 orang (50\%), dan umur $>14$ tahun ada sebanyak 8 orang $(26,67 \%)$.

Tabel 2. Distribusi Frekuensi Responden Berdasarkan Intensitas Nyeri Dismenore Sebelum Pemberian Teknik Relaksasi Nafas Dalam Pada Siswa SMAN 3 Kota Padangsidimpuan Tahun 2014

\begin{tabular}{llll}
\hline No & $\begin{array}{l}\text { Intensitas } \\
\text { Nyeri }\end{array}$ & Frekuensi & $\begin{array}{l}\text { Persentase } \\
(\%)\end{array}$ \\
\hline 1 & Ringan & 4 & 13,33 \\
2 & Sedang & 16 & 53,33 \\
3 & Berat & 10 & 33,34 \\
\hline & Total & 30 & 100 \\
\hline
\end{tabular}

Dari tabel 2 diketahui bahwa sebelum pemberian teknik relaksasi nafas dalam, responden yang merasakan intensitas nyeri ringan ada sebanyak 4 orang (13,33\%), nyeri sedang ada sebanyak $16(53,33 \%)$ orang, dan nyeri berat ada sebanyak 10 orang $(33,34 \%)$.

Tabel 3. Distribusi Frekuensi Responden Berdasarkan Intensitas Nyeri Dismenore Setelah Pemberian Teknik Relaksasi Nafas Dalam Pada Siswa SMAN 3 Kota Padangsidimpuan Tahun 2014

\begin{tabular}{llll}
\hline No & Intensitas Nyeri & Frekuensi & $\begin{array}{l}\text { Persentase } \\
(\%)\end{array}$ \\
\hline 1 & Ringan & 23 & 76,67 \\
2 & Sedang & 7 & 23,33 \\
3 & Berat & 0 & 0 \\
\hline & Total & 30 & 100 \\
\hline
\end{tabular}

Dari tabel 3 diketahui bahwa setelah pemberian teknik relaksasi nafas dalam, responden yang merasakan intensitas nyeri ringan ada sebanyak 23 orang (76,67\%), nyeri sedang ada sebanyak 7 orang $(23,33 \%)$, dan nyeri berat tidak ada $(0 \%)$.

\section{Analisis Bivariat}

Analisis bivariat dilakukan untuk mengetahui pengaruh teknik relaksasi nafas dalam terhadap penurunan intensitas nyeri dismenore dengan menggunakan Uji T Berpasangan. Hasil analisis bivariat dalam penelitian ini adalah sebagai berikut: 
Tabel 4. Hasil Analisa Pengaruh Teknik Relaksasi Nafas Dalam Terhadap Intensitas Nyeri Dismenore Pada Siswi SMAN 3 Padangsidimpuan Tahun 2014

\begin{tabular}{llll}
\hline Intensitas Nyeri & Mean \pm SD Beda MeanP Value \\
& & \\
\hline $\begin{array}{l}\text { Sebelum Teknik } 6,00 \pm 1,74 \\
\text { Relaksasi Nafas Dalam }\end{array}$ & & \\
Setelah Teknik $3,07 \pm 1,31$ & 2,93 & 0,001 \\
Relaksasi Nafas Dalam & & \\
\hline
\end{tabular}

Tabel 4 menunjukkan setelah dilakukan teknik relaksasi nafas dalam maka intensitas nyeri dismonere mengalami penurunan dibandingkan sebelum dilakukan teknik relaksasi nafas dalam. Rerata intensitas nyeri dismenore menurun dari $6,00 \pm 1,74$ menjadi 3,07 $\pm 1,31$ setelah dilakukan teknik relaksasi nafas dalam. Secara statistik dengan uji $\mathrm{t}$ berpasangan terdapat perbedaan bermakna dengan $p$ value $0,001(<0,05)$.

\section{Pembahasan}

Pada penelitian ini didapatkan setelah dilakukan teknik relaksasi nafas dalam maka intensitas nyeri dismenore mengalami penurunan dibandingkan sebelum dilakukan teknik relaksasi nafas dalam. Rerata intensitas nyeri dismenore menurun dari 6,00 $\pm 1,74$ menjadi 3,07 \pm 1,31 setelah dilakukan teknik relaksasi nafas dalam. Secara statistik dengan uji t berpasangan terdapat perbedaan bermakna dengan $p$ value $0,001(<0,05)$.

Dari tabel distribusi frekuensi didapatkan bahwa sebelum pemberian teknik relaksasi nafas dalam, responden yang merasakan intensitas nyeri ringan ada sebanyak 4 orang $(13,33 \%)$, nyeri sedang ada sebanyak 16 $(53,33 \%)$ orang, dan nyeri berat ada sebanyak 10 orang $(33,34 \%)$. Setelah pemberian teknik relaksasi nafas dalam, responden yang merasakan intensitas nyeri ringan ada sebanyak 23 orang $(76,67 \%)$, nyeri sedang ada sebanyak 7 orang $(23,33 \%)$, dan nyeri berat tidak ada $(0 \%)$.

Hal ini menunjukkan bahwa pemberian relaksasi nafas dalam memiliki pengaruh yang sangat baik terhadap penurunan intensitas nyeri dismenore.

Desain penelitian dengan pre test and post test non equivalent control group design merupakan kelemahan dalam penelitian ini. Yang menjadi keterbatasan dalam penelitian ini adalah kesulitan dalam melakukan pendekatan terhadap siswi untuk menyepakati waktu pelaksanaan relaksasi nafas dalam.

Kekuatan penelitian ini adalah perlakuan benar - benar dilakukan sesuai dengan teori, tidak menggunakan alat, murah, tidak memerlukan bantuan orang lain, gampang dilaksanakan serta tidak memberikan efek samping.

Teknik relaksasi nafas dalam dapat mengendalikan nyeri dengan meminimalkan aktifitas simpatik dalam system saraf otonom. Remaja dapat meningkatkan aktifitas komponen saraf parasimpatik vegetative secara stimultan. Teknik tersebut dapat mengurangi sensasi nyeri dan mengontrol intensitas reaksi remaja terhadap rasa nyeri. Hormone adrenalin dan kortisol yang menyebabkan stress akan menurun, remaja dapat meningkatkan konsentrasi dan merasa tenang sehingga memudahkan untuk mengatur pernafasan sampai frekuensi pernafasan kurang dari 60-70 x/menit. Kadar PaCo2 akan meningkat dan menurunkan $\mathrm{PH}$ sehingga akan meningkatkan kadar oksigen dalam darah (Smith, 2007).

Pada kondisi rileks tubuh akan menghentikan produksi hormon adrenalin dan semua hormon yang diperlukan saat stress. Karena hormon seks esterogen dan progesteron serta hormon stres adrenalin diproduksi dari blok bangunan kimiawi yang sama. Ketika kita mengurangi stres maka mengurangi produksi kedua hormon seks tersebut. Jadi, perlunya rileksasi untuk memberikan kesempatan bagi tubuh untuk memproduksi hormon yang penting untuk mendapatkan haid yang bebas dari nyeri (Sigit, 2010).

Dengan merelaksasikan otot- otot skelet yang mengalami spasme yang disebabkan oleh peningkatan prostaglandin sehingga terjadi vasodilatasi pembuluh darah dan akan meningkatkan aliran darah ke daerah yang mengalami spasme dan iskemik (Smeltzer, 2002).

Teknik relaksasi nafas dalam mampu merangsang tubuh untuk melepaskan opoiod endogen yaitu endorphin dan enkefalin.

Prinsip yang mendasari penurunan nyeri oleh teknik relaksasi terletak pada fisiologi system saraf otonom yang merupakan bagian dari sistem saraf perifer yang mempertahankan homeostatis lingkungan internal indvidu. Pada saat terjadi pelepasan mediator seperti bradikilin, prostagandin dan substansi $\mathrm{p}$, akan merangsang saraf simpatis sehingga menyebabkan vasokonstriksi yang akhirnya meningkatkan tonus otot yang menimbulkan berbagai efek seperti spasme otot yang akhirnya menekan pembuluh darah, mengurangi aliran darah dan meningkatkan kecepatan metabolisme otot yang menimbulkan pengiriman impuls nyeri dari medulla spinalis ke otak akan dipersepsikan sebagai nyeri (Tamsuri, 2007).

Menurut Smith (2007), setiap manusia mengambil 20,96\% oksigen dengan volume tidal $350 \mathrm{ml}$, maka dalam satu detik manusia mengambil oksigen sebesar 73,36 ml. Dengan memaksimalkan pengembangan paru-paru maka didapatkan volume inspirasi maksimal adalah $3000 \mathrm{ml}$ dengan bernafas maka hemoglobin yang akan lebih banyak mengikat oksigen dengan perkiraan bahwa 1,34 ml x jumlah hb/g, bila $\mathrm{Hb} 14 x 350 \mathrm{ml}=6566$ $\mathrm{g}$ oksigen per detik yang terbawa oleh darah ke seluruh tubuh. Fungsi hemoglobin adalah mengikat oksigen dari paru-paru untuk diedarkan ke seluruh jaringan tubuh dan mengikat karbon dioksida dari jaringan tubuh dikeluarkan melalui paru-paru, jadi nafas dalam berguna sebagai sarana meditasi atau distraksi, sehingga focus pikiran pasien dialihkan terhadap nyeri sekaligus mengoptimalkan penghirupan oksigen bagi sel-sel yang mengalami stress atau injury.

\section{KESIMPULAN DAN SARAN}

\section{Kesimpulan}

1. Dari hasil penelitian didapatkan bahwa umur menarche responden < 11 tahun ada sebanyak 7 orang $(23,33 \%)$, umur $11-13$ tahun ada 
sebanyak 15 orang (50\%), dan umur $>14$ tahun ada sebanyak 8 orang $(26,67 \%)$.

2. Dari hasil penelitian didapatkan bahwa sebelum pemberian teknik relaksasi nafas dalam, responden yang merasakan intensitas nyeri ringan ada sebanyak 4 orang $(13,33 \%)$, nyeri sedang ada sebanyak $16(53,33 \%)$ orang, dan nyeri berat ada sebanyak 10 orang $(33,34 \%)$ maka mayoritas responden merasakan intensitas nyeri sedang yaitu sebanyak 16 orang $(53,33 \%)$.

3. Dari hasil penelitian didapatkan bahwa setelah pemberian teknik relaksasi nafas dalam, responden yang merasakan intensitas nyeri ringan ada sebanyak 23 orang $(76,67 \%)$, nyeri sedang ada sebanyak 7 orang $(23,33 \%)$, dan nyeri berat tidak ada (0\%), maka mayoritas responden merasakan intensitas nyeri ringan sebanyak 23 orang $(76,67 \%)$.

4. Dari hasil penelitian berdasarkan hasil analisis bivariat dengan menggunakan uji $T$ Berpasangan didapatkan adanya perbedaan nilai rerata intensitas nyeri sebelum dan setelah perlakuan sebesar 2,93. Dari hasil analisis statistik dengan menggunakan uji $\mathrm{T}$ Berpasangan didapatkan nilai $\mathrm{P}=0,001<$ $\alpha=0,05$ dimana ada perbedaan bermakna antara pre dan post intervensi, maka dapat disimpulkan bahwa ada pengaruh pemberian relaksasi nafas dalam yang signifikan terhadap penurunan intensitas nyeri dismenore pada Siswa SMA 3 Kota Padangsidimpuan.

\section{Saran}

1. Perlunya sosialisasi berkelanjutan kepada siswi untuk pelaksanaan relaksasi nafas dalam sehingga siswa dapat mandiri melakukan sendiri relaksasi nafas dalam guna penurunan intensitas nyeri dismenore.

2. Perlunya pendekatan berkesinambungan kepada siswi untuk menanamkan pentingnya pelaksanaan relaksasi nafas dalam terhadap penurunan intensitas nyeri menstruasi.

3. Perlu dillakukan penelitian lanjutan dengan mengembangkan desain penelitian dan eksperimen.

4. Mengingat kekuatan dari penelitian ini, maka responden yang telah mendapat perlakuan agar menyebarluaskan manfaat relaksasi nafas dalam kepada wanita yang membutuhkan.

\section{DAFTAR PUSTAKA}

Alimul A. 2006. Pengantar Kebutuhan Dasar Manusia. Surabaya: Salemba Medika.

Arikunto, S. 2003. Prosedur Penelitian: Suatu Pendekatan Praktek . Edisi IV. Jakarta: Rineka Cipta.
Arrasid. 2007. Studi Kasus Gambaran Penatalaksanaan nyeri pada pasien Tn. $H$ Dengan Post Appendiktomi di Ruang Nusa IndahRSUD Majalengka.

Bobak. 2004 Maternity and Gynekologi , Jakarta : EGC Widjanarko,Bambang. 2006. Tinjauan Terapi Pada Dismenore Primer. Majalah Kedokteran Damianus. Vol.5. No.1 Januari

Bruner \& Sudart. 2002. Buku Ajar Keperawatan Medikal Bedah, Jakarta : EGC

Mansjoer A. dkk. 2002. Kapita Selekta Kedokteran. Jilid 2. Jakarta: Media Aesculapius.

Notoatmodjo, S. (2003). Pengantar Pendidikan Kesehatan dan Ilmu perilaku Kesehatan . Jakarta: Rineka Cipta.

Perry, AG, Potter PA .2005. Buku Ajar Fundamental Keperawatan;Konsep, Proses dan Praktik, Vol.2 Alih Bahasa. Editor Monica Ester Dkk, Jakarta : EGC

Prawirohardjo, S.(2002). Ilmu Kandungan. Edisi 2.Jakarta: Yayasan Bina Pustaka.

Price S, Wilson LM. 2006. Patofisiologi ; Konsep Klinis Proses-proses Penyakit, Vol I.Jakarta.EGC.

Priharjo, R. 2003. Perawatan Nyeri. Jakarta. EGC

Sastroasmoro S. 2011. Dasar-dasar Metodologi penelitian klinis. Jakarta: CV.Sagung seto.

Sherwood L. Fisiologi manusia. Ed 6. Jakarta: EGC; 2012

Smeltzer \& Bare 2002. Keperawatan Medikal Bedah. Edisi 8. Vol 1. Alih Bahasa Agung Waluyo. Jakarta. EGC

Smeltzer \& Bare 2002. Keperawatan Medikal Bedah. Edisi 8. Vol 2, EGC. Jakarta.

Smith D, 2007. Terapi Pernafasan untuk Penderita Asma. Prestasi Pustaka

Sigit NP. 2010. Konsep dan Proses Keperawatan Nyeri. Edisi 1. Graha Ilmu. Yogyakarta

Tamsuri A, 2007. Konsep dan Penatalaksanaan Nyeri. Jakarta. EGC

Wicaksono, H. (2004). Ilmu Kebidanan. Edisi 3. Jakarta: Yayasan Bina Pustaka.

Wirya I, Sari MD, 2013, Pengaruh Pemberian Masase Punggung Dan Teknik Relaksasi Nafas Dalam Terhadap Penurunan Intensitas Nyeri Pada Pasien Post Appendiktomi Di Zaal C Rs Hkbp Balige Tahun 2011, Jurnal Keperawatan HKBP Balige, Vol.1 No.1, Juni 2013 ISSN 2338-369091. 